\title{
DO MITO DA LÍNGUA ÚNICA À POLÍTICA DO PLU- RILINGUISMO: DESAFIOS NA IMPLEMENTAÇÃO DE LEIS DE COOFICIALIZAÇÃO LINGUÍSTICA EM MUNICÍPIOS BRASILEIROS
}

Julia lzabelle Silva

(UFSC)

\section{RESUMO}

Neste artigo, debatem-se os desafios encontrados na consolidação das políticas de cooficialização de línguas em municípios brasileiros. Para isso, discute-se o modo como as línguas constituíram objetos de regulação jurídica a favor de projetos eurocêntricos e coloniais, contribuindo, assim, para a fundação do mito da unicidade e homogeneidade linguística. Além disso, é apresentado o modo como as tendências pluralistas das últimas décadas impulsionaram outro olhar para o plurilinguismo, enfatizando, assim, a emergência dos movimentos étnicos e dos novos direitos, dentre eles o direito linguístico, como marcos desse momento de diversificação das pautas de luta. A análise de três processos de implementação da lei de cooficialização permite identificar tensionamentos nas relações entre as comunidades linguísticas e o Estado.

PALAVRAS-CHAVE: política linguística; cooficialização; implementação.

\section{Introdução}

Pouco se questiona sobre quantas e quais línguas são faladas no Brasil. Não há dúvidas, para grande parte da população brasileira, de que 
é a língua portuguesa, herança da antiga metrópole, Portugal, o idioma de todos os brasileiros. Alguns arriscariam falar da influência de línguas indígenas e quem sabe das línguas afro-brasileiras. Para falar da atual situação linguística do Brasil, importa trazer um dado histórico: no período inicial da colonização brasileira, estima-se que fossem faladas cerca de 1.500 línguas indígenas (RODRIGUES, 2002). Soma-se a isso o período da escravidão, que trouxe falantes de línguas de diversas etnias africanas e, já nos séculos XIX e XX, com as imigrações, falantes de diferentes línguas europeias. De modo resumido, podemos dizer que, do processo de extermínio dos povos indígenas que ocorrera no Brasil e das políticas linguísticas de assimilação e integração que caracterizaram o indigenismo do Estado brasileiro, restaram hoje cerca de duzentas e setenta e quatro línguas indígenas, faladas por 315 etnias distintas (IBGE, 2010).

Além das línguas indígenas, outras 70 línguas são línguas de interação diária de brasileiros pertencentes a comunidades descendentes de imigrantes (alemão, italiano, japonês, polonês etc), comunidades quilombolas (línguas crioulas) e comunidades surdas (Língua Brasileira de Sinais e língua indígena de sinais Urubu-Kaapor). Ao contrário do que se costuma acreditar, essas línguas não estão no passado, mas ainda hoje constituem e são constituídas pelas identidades dos sujeitos que as falam. Nesse sentido, pensar o Brasil como um país de uma única língua e um único povo, como preconizavam os ideais romântico-nacionalistas do século XIX, não representa outra coisa senão um mito, uma narrativa que impera sobre uma suposta unidade e identidade nacional.

Paradoxalmente, nas últimas décadas, o avanço de um neocolonialismo, mais globalizado, e dos processos de homogeneização que dele resultam tem produzido práticas de resistências cada vez mais organizadas. Observamos uma politização das questões étnicas e das temáticas pluralistas, de modo geral. Como sujeitos históricos e políticos, os movimentos étnicos têm-se mobilizado e assumido uma postura agenciadora frente às decisões tomadas pelos Estados, o que significa não mais aceitar as políticas de apagamento e exclusão que caracterizaram os processos colonizatórios, mas reivindicar um protagonismo político nas decisões que interferem no rumo de suas vidas. Nesse marco, a questão do plurilinguismo surge como uma importante pauta para os grupos interessados na construção de um Estado mais pluralista e democrático.

Diante dessa problemática, neste artigo, intentaremos trazer, para o campo das discussões político-linguísticas, o processo de consolidação 
do plurilinguismo e do direito linguístico no Brasil. Temos consciência da fundamental relevância que o movimento pela Língua Brasileira de Sinais teve e ainda tem no delineamento das discussões e decisões sobre Direitos Linguísticos no Brasil. No entanto, dada a complexidade da área, que já trilhou um longo caminho, e a sua dimensão (que ocorre em nível federal), optamos por abordar os processos de cooficialização de línguas que ocorrem em nível municipal. Com isso, buscamos trazer alguns apontamentos sobre os desafios e as dificuldades enfrentadas na consolidação do(s) movimento(s) por Direitos Linguísticos no Brasil.

1. Uma nação, um Estado, uma língua: construindo o mito da unicidade linguística

Não é difícil imaginar o papel que as línguas desempenharam nos processos de dominação e homogeneização que marcaram as relações colonizatórias. Nesses contextos, a língua funcionara como um elemento fundamental no agenciamento de práticas políticas de controle e subjugação dos povos que habitavam as colônias das metrópoles europeias. Segundo Anderson (2008), já no século XIX, o critério linguístico, junto com outros critérios como cultura, religião e etnia, esteve na base do surgimento da concepção moderna de Estado, representada pela figura do Estado-nação. De acordo com o autor, a concepção moderna de nação foi construída a partir de um conjunto de narrativas, discursos e imagens que buscavam criar um sentimento de identificação cultural entre os indivíduos.

Assim, foram construídos mitos que permitiram que pessoas que nunca se-haviam conhecido se identificassem como pertencentes a uma mesma comunidade, a qual compartilhava de um passado glorioso, uma cultura, uma história e uma língua, unindo-as como um só povo. Conforme ressalta Anderson (2008), sentir-se representado por essas narrativas permitiu a criação de um sentimento de identificação com um passado comum, fundamental para a consolidação do Estado-nação (ANDERSON, 2008).

O controle exercido pelo Estado na consolidação das línguas nacionais também ocorreu no contexto da formação dos novos Estados americanos do final do século XVIII e início do século XIX. A diversidade de línguas e povos étnicos que se encontrava na América Latina não impediu que o modelo do nacionalismo europeu fosse reproduzido. Segundo Bessa Freire (1983) e Mariani (2004), no Brasil, entre os séculos XVI e XVII, a chamada Língua Geral, de base tupi, chegou a ser predominante, como a língua de comunicação interétnica, sobretudo "por parte de reli- 
giosos, indígenas de povos variados, escravos, mulheres e crianças brancas" (MARIANI, 2004, p. 35). Para Bessa Freire, a expansão da língua geral, até 1.700, incentivada pela metrópole, chegou a afetar a função da própria língua portuguesa, o que passou a preocupar a coroa portuguesa em relação à hegemonia de sua língua na colônia. Segundo o autor, isso foi suficiente para que o Marquês de Pombal considerasse que a Língua geral representava uma ameaça à Língua do Príncipe, o português. Assim, a fim de consolidar a autoridade da coroa portuguesa e de sua língua, Pombal estabelece, no art. 6 do Diretório dos Índios, a obrigatoriedade do uso da "Língua do Príncipe", proibindo o uso da Língua Geral ou de qualquer outra língua indígena.

Portanto, observa-se que, para garantir a unidade linguística da nação, foi preciso um ato político-jurídico que legislasse sobre a institucionalização da língua portuguesa e que, ao mesmo tempo, proibisse/ controlasse o uso das demais línguas (MARIANI, 2004). O processo de oficialização da língua portuguesa, por ser impositivo, coagiu e controlou os sujeitos sociais, na medida em que proibiu o uso de suas línguas, apontadas como não civilizadas, ilegítimas, "diabólicas", e os obrigou a aprender outra - o português, língua do príncipe e da nação. Como afirma Mariani (2004), trata-se de um projeto de colonização linguística, construído a partir do imaginário em torno da relação língua-nação, e que teve como intenção explícita a eliminação não só das línguas, mas das populações indígenas.

Segundo Oliveira (2002), mesmo após os movimentos de independência, nenhum dos governos republicanos que se seguiram questionou o decreto de Pombal. A língua portuguesa continuou a ser a língua oficial da nação brasileira, muito embora novos discursos estivessem sendo construídos para essa língua. Assim, a "língua do povo", da "nação brasileira", ainda que perpassada pelo imaginário de um passado heroico e indígena, continuava a silenciar os cidadãos brasileiros falantes de outras línguas (cf. BESSA FREIRE, 1983; MARIANI, 2004). De acordo com Oliveira, tanto o Estado português como, após a independência, o Estado brasileiro, adotaram uma série de políticas de repressão linguística. Como menciona o autor, "a história linguística do Brasil poderia ser contada pela sequência de políticas linguísticas homogeneizantes e repressivas e pelos resultados que alcançaram. [...] das 1.078 línguas faladas no ano de 1500 , ficamos com cerca de 170 no ano 2000”. (OLIVEIRA, 2002, p. 84) 
Não apenas os índios sofreram com as políticas de repressão linguística. O regime ditatorial de Getúlio Vargas proibiu o uso das línguas faladas nas comunidades de imigrantes, especialmente o alemão e o italiano, falados, sobretudo, no sul do país ${ }^{1}$. Sem contar com as línguas sinalizadas dos surdos, que sempre foram alvo de discriminação e repressão linguística. No entanto, todo esse processo de repressão às línguas não aconteceu sem resistências. Muitos grupos continuaram a usar suas línguas em seus afazeres cotidianos, no interior de seus lares, no segredo de suas vidas domésticas. Nas últimas décadas, essa resistência tem tomado uma dimensão política organizada, de forma que o que antes se restringia ao domínio privado e doméstico passa agora a alcançar o domínio público e legal.

\section{Consolidação dos Direitos linguísticos no Bra- sil: a legalidade como estratégia de luta}

Nas últimas décadas, temos presenciado movimentos que, aparentemente, estão em direções contrárias. De um lado, a expansão da lógica capitalista de mercantilização, dos novos colonialismos que excluem e marginalizam com processos cada vez mais globalizantes e totalizantes. Do outro lado, insurgem mobilizações emancipatórias que reivindicam o reconhecimento da diversidade étnica, cultural e linguística, de direitos não somente individuais, como coletivos. Ecoam as vozes de diversos sujeitos sociais, que intentam serem ouvidos pelas suas pautas de luta, sejam elas de orientação classista, étnica, feminista etc. Para Boaventura de Sousa Santos (2010b), o capitalismo transnacional e o neocolonialismo produzem dinâmicas de mobilidade, fluxos migratórios e de informação que permitem o compartilhamento de experiências e histórias distintas. Essa articulação entre diferentes lutas coletivas, em diferentes escalas, locais, regionais e nacionais, impulsionam o debate em torno de novas definições de cidadania, direito, justiça e identidade.

Assim, não se trata mais de resistir, passivamente, às mudanças que ocorrem ao redor do mundo, mas de, a partir dessas mudanças, organizar-se politicamente. Diferentes grupos étnicos buscam, a partir da legislação internacional disponível, garantir o direito de serem diferentes. Tais movimentos produzem, no entanto, uma tensão para o Estado moderno, tradicionalmente embasado nos preceitos ocidentais e individualistas do direito. Essa tradição, como bem aponta Mignolo (2003), está relacionada à colonização epistêmica ocorrida nos países colonizados. A colonialida- 
de epistêmica, segundo o autor, diz respeito à construção de um imaginário que coloca os valores, as culturas, as línguas, as religiões e os conhecimentos produzidos na Europa ocidental como sendo os únicos legítimos. Ao mesmo tempo, ela invisibiliza todo o conjunto de narrativas, histórias, conhecimentos e subjetividades das populações subalternizadas. Segundo o autor, como instituição da modernidade ocidental, o direito internacional cumpriu um importante papel na legitimação da inferiorização dos povos colonizados, tidos como bárbaros, primitivos etc. (MIGNOLO, 2003)

No entanto, a desconstrução desse imaginário é um fator que, como alerta Mignolo, tem possibilitado uma descolonização do conhecimento e do próprio direito. Assim, os movimentos sociais, tais como os indígenas na América Latina, têm produzido fraturas, quebras epistêmicas que desconstroem a universalidade dos valores europeus/ocidentais, e visibilizam a pluralidade das histórias subalternas e suas subjetividades. Para Santos (2010b), é nesse contexto de desconstrução da universalidade de conceitos eurocêntricos, como Direito, Estado e Cultura, que vemos surgir diferentes estratégias de resistência e de luta - lutas feministas, indígenas, pós-coloniais. De acordo com o autor,

a ideia de movimento, de articulação de diferenças, de emergência de configurações culturais baseadas em contribuições de experiências e histórias distintas tem levado a explorar as possibilidades emancipatórias do multiculturalismo, alimentando os debates e iniciativas sobre novas definições de direitos, de identidades, de justiça e de cidadania. (SANTOS, 2010b, p. 33)

É a partir dessa proposta de uso do direito como instrumento emancipatório que as comunidades linguísticas têm-se organizado para reivindicar seus direitos linguísticos. Embora a Declaração Universal dos Direitos Humanos de 1948 e diversos outros pactos e convenções internacionais façam menção ao direito linguístico, é na Declaração Universal dos Direitos Linguísticos, produzida em 1996, que podemos encontrar apontamentos específicos sobre o tema. Dentre as disposições do documento, o artigo $3^{\circ}$, parágrafos 1 e 2 , estabelece:

[..] o direito a ser reconhecido como membro de uma comunidade linguística; o direito ao uso da língua em privado e em público; o direito ao uso do próprio nome; o direito a relacionar-se e associar-se com outros membros da comunidade linguística de origem; o direito a manter e desenvolver a própria cultura; [...] o direito ao ensino da própria língua e da própria cultura; o direito a dispor de serviços culturais; 
o direito a uma presença equitativa da língua e da cultura do grupo nos meios de comunicação; o direito a serem atendidos na sua língua nos organismos oficiais e na relações socioeconômicas. (OLIVEIRA, 2003. p. 25-26)

A declaração, que representa atualmente o principal documento internacional de direitos linguísticos, enfatiza o reconhecimento de direitos tanto individuais quanto coletivos das comunidades linguísticas. Dentre os diversos princípios estabelecidos, considera-se a importância de se corrigirem os desequilíbrios linguísticos causados pela ocupação, colonização, invasão e demais processos de subordinação política, econômica e cultural a que estiveram submetidos esses grupos, promovendo, para isso, suas línguas em contextos tanto privados como públicos. (OLIVEIRA, 2003)

Embora o Brasil possua uma constituição ainda tímida em relação à definição de direitos linguísticos, se comparada a constituições como a boliviana, por exemplo, que reconhece o seu caráter plurilíngue, no que diz respeito aos direitos dos povos indígenas, no artigo 231 do texto constitucional é possível encontrar a seguinte menção à questão linguística:

são reconhecidos aos índios sua organização social, costumes, línguas, crenças e tradições, e os direitos originários sobre as terras que tradicionalmente ocupam, competindo à União demarcá-las, proteger e fazer respeitar todos os seus bens. (BRASIL, 1998 - grifo nosso)

Além disso, no artigo 210, parágrafo $2^{\circ}$, referente à Educação Escolar Indígena, define-se que "o ensino fundamental regular será ministrado em língua portuguesa, assegurada às comunidades indígenas também a utilização de suas línguas maternas e processos próprios de aprendizagem" (BRASIL, 1998 - grifo nosso). Cabe pontuar que, ainda que a Constituição brasileira assegure o direito ao uso e ao ensino das línguas indígenas, assim como também reconhece o status de língua nacional à Língua Brasileira de Sinais (LIBRAS) ${ }^{2}$, o português continua sendo a única língua oficial do Estado brasileiro. Além disso, no texto constitucional não há nenhuma menção às demais línguas faladas em território brasileiro, tais como as línguas de imigração e as línguas crioulas.

Contudo, a existência de um quadro jurídico internacional favorável ao plurilinguismo como direito coletivo e a crescente politização das questões de diversidade étnica contribuíram para que, no Brasil, as minorias linguísticas começassem a reivindicar o direito ao uso de suas línguas 
em contextos públicos e oficiais. Conforme ressalta Morello (2015), "a redemocratização do país e a Constituição de 1988 abriram espaço, timidamente, para o reconhecimento de direitos culturais e linguísticos e para a visibilidade de um Brasil Pluricultural e Plurilíngue, com uma cidadania que se expressa em muitas línguas”. (MORELLO, 2015, p. 9)

O primeiro município a realizar a ação de cooficialização foi São Gabriel da Cachoeira, localizado no estado do Amazonas, na região mais plurilíngue do país. Por meio da lei $\mathrm{n}^{\circ} 145$, tornaram-se cooficiais no município as línguas baniwa, nheengatu e tucano, além da língua portuguesa, que continuou sendo oficial (MORELLO, 2015). A partir da ação de São Gabriel da Cachoeira, outros municípios, cuja parcela considerável da população é falante de outra língua além do português, seguiram os mesmos passos da cooficialização. Na tabela a seguir, é possível visualizar o quadro atual das línguas cooficializadas em municípios brasileiros:

\section{Tabela - Relação de municípios brasileiros que cooficializaram uma ou mais línguas e suas respectivas línguas cooficializadas}

\begin{tabular}{l|l}
\hline Municipio-UF & Língua(s) \\
\hline São Gabriel da Cachoeira-AM & Nheengatu, Baniwa e Tukano \\
\hline Tocantínia-TO & Akwê Xerente \\
\hline Bonfim-RR & Macuxi e Wapichana \\
Tacuru-MS & Guarani \\
\hline Pancas-ES & Pomerano \\
\hline Santa Maria de Jetibá-ES & Pomerano \\
\hline Domingos Martins-ES & Pomerano \\
\hline Laranja da Terra-ES & Pomerano \\
\hline Vila Pavão-ES & Pomerano \\
\hline Canguçu-RS & Pomerano \\
\hline Serafina Corrêa-RS & Talian \\
\hline Antônio Carlos-SC & Hunsrükisch \\
\hline Santa Maria do Herval-RS & Hunsrükisch \\
\hline Pomerode-SC & Alemão \\
\hline
\end{tabular}

Fonte: Site do Instituto de Investigação e Desenvolvimento em Política Linguística (IPOL) ${ }^{3}$ 
Segundo Oliveira (2015), cooficializar uma língua em nível municipal significa que, além do português, todos os órgãos da prefeitura e da iniciativa privada devem oferecer serviços também nas demais línguas oficiais, incluindo toda a documentação pública municipal, as campanhas publicitárias institucionais, a educação escolar, as placas de sinalização, enfim, todos os serviços básicos de atendimento ao cidadão. Isso inclui a elaboração e a aprovação de políticas públicas específicas para esse fim, inclusive a contratação de intérpretes falantes das línguas cooficiais no atendimento dos serviços públicos e privados. Abaixo, destacamos alguns pontos que Oliveira (2015) considera como as condições prévias para que outras línguas brasileiras sejam reconhecidas e, de fato, implementadas como línguas oficiais, ao lado do português:

- a oficialização da língua deve partir de uma demanda política dos grupos linguísticos, isto é, deve ser fruto do desejo da comunidade e de suas entidades representativas (organizações, conselhos etc);

- é preciso que haja compatibilidade constitucional na lei de cooficialização. $\mathrm{O}$ artigo $13^{\circ}$ da Constituição brasileira institui a língua portuguesa como língua oficial da União, porém nada diz sobre a oficialidade nos estados e municípios. Também não diz que deve ser a única língua oficial. Conquanto o português seja oficial nos municípios, tornar outras línguas oficias não configura inconstitucionalidade;

- a Câmara de Vereadores e a comunidade interessada devem elaborar projeto de regulamentação da oficialização, "que detalha o que se entende por oficialização, prioriza as ações, nomeia órgãos responsáveis pela ação (em geral cria um Conselho Municipal de Política Linguística)" (OLIVEIRA, 2015, p. 29);

- implementação: a partir da data de regulamentação, o poder público tem um prazo de 180 dias para executar a lei. Nessa fase, "é necessário planejar o tipo de normatização que (sic!) a língua será conduzida (escolha de variedades, escrituralização), bem como a formação de quadros (professores da língua, por exemplo), [...] a presença da língua nos espaços públicos, como as placas de trânsito, os atos administrativos municipais, como as campanhas de saúde e as transmissões midiáticas" 
(OLIVEIRA, 2015, p. 29);

- planejamento orçamentário, que corresponde à discussão sobre como o município alocará e captará recursos para serem destinados ao funcionamento bi ou plurilíngue das instituições.

Portanto, depois de um longo processo de luta pelo reconhecimento legal, para que essas leis não fiquem somente no papel, é preciso que órgãos municipais competentes elaborem políticas públicas específicas para a sua implementação. Porém, são muitos os fatores que intervêm na execução ou não de tais medidas e, portanto, no funcionamento da oficialização.

\section{Desafios na implementação das leis de cooficia- lização em três municípios brasileiros}

Embora se trate de uma política recente no Brasil, na literatura já é possível encontrar trabalhos que apontam as dificuldades enfrentadas na implementação das leis de cooficialização. No entanto, esses trabalhos, geralmente, estão voltados às realidades locais às quais os pesquisadores se dedicam, com apontamentos específicos para as comunidades estudadas. Uma comparação desses estudos permitiu-nos identificar problemas comuns que essas comunidades têm enfrentado em sua luta pelo reconhecimento linguístico. Nossa análise partiu dos estudos de Silva (2013) sobre a situação do Tukano, do Nheengatu e do Baniwa em São Gabriel da Cachoeira (AM), de Martines (2014) sobre o andamento da cooficialização do Guarani em Tacuru (MS), e de Morello (2015) sobre o pomerano em Santa Maria do Jetibá (ES).

De acordo com Silva (2013), o primeiro município a cooficializar outras línguas, São Gabriel Cachoeira, apresenta poucos avanços na implementação da lei. Em sua pesquisa, a autora observou que, em sua maioria, as instituições públicas e privadas não têm oferecido atendimento nas línguas cooficiais. Segundo os depoimentos dos participantes do estudo, dois dos motivos que têm impedido a efetivação da lei é o seu desconhecimento por parte da população em geral e a falta de conscientização e fiscalização por parte do poder público. Além disso, outro fator mencionado é que, quando há atendimento na língua indígena, muitas vezes, os mais velhos, por exemplo, acabam optando por falar o português. Veja o que diz esse participante, membro da FOIRN ${ }^{4}$ : 
eu acho que ainda é uma falta de conhecimento até de dizer: 'se eu não sei expressar direito meu português eu tenho que falar na minha língua'. Agora o quê que acontece como a maioria dos velhinhos consegue expressar um pouquinho em português, eles acham que têm que falar em português e não na língua deles, entendeu? Então, por isso que eu falo, ainda é questão de... falta de saber do seu direito da sua língua que você tem que falar. Porque nunca ninguém chegou a falar com alguém na sua língua numa prefeitura ou num banco, por exemplo [...] Então eu acho que falta mais divulgação desse direito que nós temos aqui em São Gabriel (SILVA, 2013, p. 85-86).

Além da denúncia que a autora faz acerca da falta de divulgação da lei no município, percebemos, nesse discurso, a persistência de uma prática linguística já muito consolidada, que é a prática de se falar o português nos espaços públicos. Entrar em um espaço institucionalizado implica, necessariamente, a utilização do português. Mas tal relação não se dá por acaso. Tal prática está intimamente relacionada ao fato de que, há séculos, as línguas indígenas e as demais outras línguas faladas no Brasil estiveram encerradas em contextos muito privados, entre as paredes das casas, no interior das relações íntimas, quase como se a língua fosse, em si, o segredo a ser contado. Se, no século XVI, o uso da língua indígena representava uma heresia, uma afronta à língua do príncipe, tal concepção colonial, como sabemos, atravessou o tempo e permaneceu no imaginário e nas práticas linguísticas dos sujeitos, de modo que, há poucas décadas, ainda tínhamos um sistema educacional que punia, com práticas de tortura, aqueles que fizessem uso de outra língua que não fosse o português.

Apesar da criação da lei de cooficialização, o estigma, o medo e a vergonha de se falar a língua indígena em público ainda persistem no imaginário e na realidade das práticas de interação cotidiana desses sujeitos. O imaginário, conforme Mignolo (2005), pode ser entendido como uma construção simbólica por meio da qual diferentes comunidades (raciais, étnicas, nacionais, religiosas etc) definem a si mesmas. Como lembra o autor, o "imaginário do mundo moderno/colonial surgiu da complexa articulação de forças, de vozes escutadas ou apagadas, de memórias compactadas ou fraturadas, de histórias contadas de um só lado [...]" (MIGNOLO, 2005, p. 40). Os discursos coloniais, que silenciam (e punem) as vozes indígenas, representadas, nesse caso, pelo uso público de suas línguas, ainda atravessam as concepções e as práticas linguísticas desses sujeitos. Assim, quando o participante afirma que "nunca ninguém chegou a falar com alguém na sua língua numa prefeitura ou num banco”, 
temos noção do modo como nossas práticas linguísticas ainda estão arraigadas na visão colonial de qual língua deve e qual língua não deve ser usada em certos contextos. Tal reflexão sobre as marcas da colonialidade é percebida no discurso desse funcionário da FOIRN:

outra coisa também é... uma história da colonização né, foram quase século de colonização né, os missionários proibiram demais a língua né, os pais que... começaram a frequentar os internatos acabaram ficando com vergonha, os padres proibiam isso e... a partir desse momento até na própria casa ele não falam mais com os filhos (SILVA, 2013, p. 86).

Nessa fala, inferimos uma consciência do próprio sujeito a respeito de sua condição pós-colonial e vemos a importância de relacionar a política linguística de cooficialização com as políticas linguísticas que definiram, ao longo dos séculos, o modo como as populações indígenas foram levadas a conceber suas línguas. Assim, talvez um dos maiores desafios para a concretização das leis de cooficialização seja justamente desconstruir no imaginário dessas populações e da população brasileira em geral, a ideologia há muito legitimada de que as suas línguas, as suas identidades, suas cosmovisões e saberes são inferiores.

Um projeto de lei que oficializa uma língua indígena já é, em si, um ato de ruptura com as políticas coloniais. No entanto, um projeto decolonial (MIGNOLO, 2003; 2005) e emancipatório (SANTOS, 2010a; 2010b) só pode ser construído legitimadamente na medida em que um pensamento descolonizado se fizer vivo nas mentes e nos corpos dos sujeitos subalternizados. Assim, não basta desconstruir a ideologia da homogeneidade linguística em isolado. É preciso desconstruir a própria razão ocidental/ colonial que define o que é legítimo e o que não é, assim como todos os valores, concepções e práticas que reproduzem essa razão. Portanto, pensar a lei de cooficialização não como um processo isolado, mas como algo que integra um projeto maior, decolonial e emancipatório, significa pensar o papel da coletividade na definição das políticas linguísticas.

Em seu estudo sobre o processo de cooficialização do Guarani em Tacuru (MS), de Martines (2014) investigou se o projeto de lei elaborado pelos vereadores indígenas fora previamente submetido à consulta da população local. Na entrevista, o professor responsável pelo projeto de lei afirmou que houve participação indireta da população na elaboração do projeto. Observe o seguinte recorte da entrevista: 
Pesquisadora: houve uma participação da comunidade indígena, professor? Uma aprovação de todos em relação à implantação da lei?

P: sim, porque na verdade, depois nós tivemos uma grande reunião, né? E o resultado, eu trouxe aqui na aldeia, é, assim, vamos dizer que antes de, antes de elaborar o projeto a gente sempre ouve a, a população né? Inclusive até alguém próprio da aldeia me perguntou? E como que vai ficar concurso público? Porque daí o não índio também vai aprender, vai falando, aí eles vão fazer e também vão passar né? (risos) (Entrevista realizada em 20 de março de 2013, MARTINES, 2014, p. 122).

No entanto, outros professores, membros da mesma equipe pedagógica a qual pertence esse professor, afirmaram não ter havido nenhuma participação no processo de decisão para a criação da lei: "Porque assim, chegou e implantou. Ninguém chegou e sentou com a comunidade escolar, pra dizer qual é o objetivo da lei, né?" (Entrevista realizada em 4 de julho de 2013, MARTINES, 2014, p. 123); "Então, pra nós, ela é uma lei que veio de cima para baixo, né? Como se diz, né? Caiu de paraquedas, né? Foi a gente teve que correr atrás e... trabalhar em cima, né? [...]" (Entrevista realizada em 18 de março de 2013, MARTINES, 2014, p. 123). As contradições entre a fala do responsável pelo projeto de lei e a fala dos outros professores revelam problemas no processo de criação, decisão e implementação da lei, já que, segundo Martines (2014), desde o seu período inicial, de decisão pela criação da lei, não houve discussão com a comunidade interessada. Além disso, a preocupação dos professores em "correr atrás" do que deve ser feito somente revela uma falta de esclarecimento sobre como se deve dar o processo de implementação.

De acordo com Santos (2010a), a realização de um projeto contra-hegemônico deve acontecer "de baixo para cima", isto é, deve partir da iniciativa e da vontade das coletividades interessadas. No entanto, o que vemos é uma política top-down, já que, nos termos dos próprios professores da comunidade, a lei "veio de cima para baixo", "caiu de paraquedas". É nesse sentido que Oliveira (2007) considera que, para que ocorra o processo de implementação, é preciso haver uma demanda e uma mobilização política por parte da comunidade como coletividade:

através de suas entidades (organização indígena, conselho do povo indígena etc.), isto é: é preciso haver a demanda política para que isto ocorra e, portanto, agentes políticos para quem a reivindicação dos direitos linguísticos faça sentido. O nível de organização política dos povos indígena, é, portanto, diretamente proporcional à possibilidade 
de um empreendimento desse tipo. (OLIVEIRA, 2007, p. 5)

Essa mesma observação é feita por Evandro Morello (2015), quando discute o processo de implementação da língua pomerana no município de Santa Maria de Jetibá. Segundo o autor, para que a lei alcance a sua máxima eficácia, é preciso que a comunidade entenda o significado e a importância que ela pode ter para as suas vidas, "sobretudo, pelos benefícios que ela pode trazer em proveito de todos, seja pela valorização da cultura local, seja pelo potencial socioeconômico que isso pode gerar no Município" (MORELLO, 2015, p. 40). Assim, embora muitas ações político-educacionais estejam sendo desenvolvidas pelo próprio quadro de profissionais pomeranos (professores, agentes pedagógicos, vereadores etc), um dos desafios apontados pelo autor é garantir que a comunidade como um todo se envolva com o projeto, de modo que o "conteúdo [da lei] deve expressar claramente aquilo que a comunidade efetivamente deseja" (MORELLO, 2015). Segundo o autor,

o que se pretende é alcançar a máxima eficácia da lei, não pelo seu caráter coercitivo, sancionatário, mas sim pelo seu caráter educativo e orientativo e pelo envolvimento da comunidade com suas práticas, hábitos e costumes que vão legitimar a própria lei. (MORELLO, 2015, p. 40)

Nesse trecho, Morello toca em um ponto importante do processo: o caráter coercitivo e sancionatário da lei é um problema que pode acabar invertendo o propósito da cooficialização. Assim, o que era para ser uma estratégia de legitimação das práticas da comunidade pode-se tornar mais um mecanismo legal de sancionamento. Isto é, se a lei não for elaborada a partir daquilo que a comunidade legitima como importante para si, sua aplicação não será o resultado de suas demandas e desejos; será somente uma ação coercitiva que obriga o uso de determinada língua. Como ressalta Santos (2010b), ao reivindicar o direito (linguístico), uma categoria historicamente hegemônica e colonial, as lutas emancipatórias devem utilizá-lo de maneira contra-hegemônica. Isso significa que as leis devem resultar e devem estar a serviço das necessidades dos povos subalternos, em uma clara estratégia de oposição à dominação colonial e de legitimação de seus saberes e práticas (SANTOS, 2010b). 


\section{À Guisa de conclusão: tensionamentos anunciados}

A cooficialização em São Gabriel da Cachoeira e os movimentos pelas línguas que, em seguida, irromperam em diversas partes do país, constituem-se sob o signo da ruptura com os fundamentos da sociedade colonial e do Estado moderno de base eurocêntrica. Ao reivindicar o uso de suas línguas em contextos oficiais e públicos, os movimentos étnicos afirmam sua legitimidade linguística, identitária e política perante o Estado. Identificamos um novo padrão de relação política, no qual os grupos étnicos buscam um maior protagonismo e autonomia em suas relações com o Estado. Desse modo, não é mais o plurilinguismo o problema a ser resolvido pelos moldes do Estado-nação homogêneo e centralista, mas é o próprio Estado o modelo institucional a ser reformulado a partir das demandas populares e pluralistas.

Contudo, iniciativas emancipatórias sempre vêm acompanhadas de desafios e de tensionamentos (SANTOS, 2010a; 2010b). Embora os movimentos étnicos estejam levantando suas bandeiras por uma transformação do Estado, e acreditamos que as leis de cooficialização no Brasil se inserem nesse contexto, existem muitas dificuldades a serem superadas, afinal, "não é fácil transformar radicalmente uma instituição que, em sua forma moderna, tem mais de trezentos anos" (SANTOS, 2010a). Refundar o Estado, para usar os termos de Santos (2010a), não implica somente mudar as estruturas políticas e econômicas, mas requer também mudar as relações sociais e culturais, os símbolos, as mentalidades, epistemes e subjetividades que configuram relações de colonialidade.

As políticas de cooficialização de línguas nos municípios produzem tensões entre movimentos étnicos e o Estado, já que, embora atuem na legalidade, o que esses grupos reivindicam, em última instância, é a descolonização do preceito de homogeneidade que fundamenta o Estado-nação. Assim, cabe perguntar até que ponto o Estado brasileiro e os seus agentes institucionais estão preparados para reconhecer a institucionalidade de outras línguas? Estariam o Estado e a sociedade em geral preparados para disponibilizar parte do orçamento de seu município para a contratação de intérpretes, por exemplo? Enfim, para além das transformações legais e organizacionais que a cooficialização de uma língua pressupõe e implica, podemos identificar mudanças, descolonizações e desconstruções nas relações sociais, nos símbolos e nas mentalidades das pessoas? 
O mito da unicidade e da unidade linguística constituiu e ainda hoje constitui parte de um imaginário sobre a nação e sobre as identidades nacionais. Os desafios, sejam eles legais, institucionais ou ideológicos, devem permanecer ainda por um longo período. No entanto, é nesse tensionamento entre ruptura e continuidade, entre colonialidade e pós-colonialidade, que a luta se constrói e se fortalece. Descolonizar as práticas, as mentes e os corpos do Estado e da sociedade brasileira continua sendo o maior desafio para as políticas de cooficialização de línguas no Brasil.

\section{FROM THE MYTH OF THE SINGLE LANGUAGE TO THE PLURILINGUALISM POLICY: CHALLENGES IN THE LAW ENFORCEMENT OF THE CO-OFFICIALIZING PROCESS OF LANGUAGES IN BRAZILIAN COUNTIES}

\section{ABSTRACT}

In this article, we reflect on the challenges faced by the establishment of the politics of linguistic co-officializing in Brazilian counties, by discussing how languages constituted objects of legal regulation in favor of colonial and Eurocentric projects, contributing, thereby, to the foundation of the myth of unity and linguistic homogeneity. Moreover, we present how the pluralist tendencies of the last decades have driven another view of the plurilingualism, emphasizing, thus, the emergence of ethnic movements and of the new rights, including language rights, as milestones in this moment of diversification of the agenda of class struggle. The analysis of three processes of the law enforcement allows us to identify tensions in the relations between the linguistic communities and the State. KEYWORDS: language policy; coofficializing process; enforcement. 


\section{REFERÊNCIAS}

ANDERSON, Benedict. Comunidades Imaginadas: reflexões sobre a origem e difusão do nacionalismo. São Paulo: Companhia das Letras, 2008.

BESSA FREIRE, José Ribamar. Da "fala boa" ao português na Amazônia brasileira. Revista Ameríndia, n. 8, 1983.

BRASIL. Constituição (1988). Constituição da República Federativa do Brasil. Brasília, DF: Senado, 1988.

. Lei $\mathrm{n}^{\circ} 10.436$, de 24 de abril de 2002.

. Ministério do Planejamento, Orçamento e Gestão. Instituto Brasileiro de Geografia e Estatística. O Brasil indígena, 2010. Disponível em: http:// indigenas.ibge.gov.br/estudos-especiais-3/o-brasil-indigena/lingua-falada Acesso em: abril de 2016.

MARIANI, Bethania. Colonização Linguística. Campinas, SP: Pontes, 2004.

MARTINES, Lilian C. do Amaral. A política linguística de cooficialização da língua guarani em Tacuru/MS e seus desdobramentos políticos, sociais e pedagógicos. Ponta Grossa: UEPG, 2014. Dissertação (Mestrado em Linguagem, identidade e subjetividade) - Programa de Pós-Graduação em Linguagem, identidade e subjetividade, Universidade Estadual de Ponta Grossa, Ponta Grossa, 2014. MIGNOLO, Walter. Histórias Locais/Projetos Globais. Belo Horizonte, UFMG, 2003.

A colonialidade de cabo a rabo: o hemisfério ocidental no horizonte conceitual da modernidade. In: MIGNOLO, Walter. A colonialidade do saber: eurocentrismo e ciências sociais: Perspectivas latino-americanas. Buenos Aires: CLACSO, 2005.

MORELLO, Evandro José. Cooficialização da língua pomerana no Município de Santa Maria do Jetibá/ES. A linguagem como patrimônio cultural imaterial. Competência do Município para legislar sobre proteção a bens culturais. Elementos para maior eficácia da lei. In: MORELLO, Rosângela. Leis e línguas no Brasil: o processo de cooficialização e suas potencialidades. Florianópolis: IPOL, 2015, p. 33-41.

MORELLO, Rosângela. (Org.). Leis e línguas no Brasil: o processo de cooficialização e suas potencialidades. Florianópolis: IPOL, 2015.

OLIVEIRA, Gilvan Müller. Brasileiro fala português: monolinguismo e preconceito linguístico. In: SILVA, Fábio Lopes; MOURA, Heronides Melo. O direito à fala: a questão do preconceito linguístico. $2^{\mathrm{a}}$ ed. Florianópolis: Insular, 2002. 
(Org.). Declaração Universal dos Direitos Linguísticos: novas perspectivas em política linguística. Campinas, SP: Mercado de Letras; Florianópolis: IPOL, 2003.

. Oficialização de línguas em nível municipal no Brasil - algumas considerações político-linguísticas e jurídicas preliminares. In: OLIVEIRA, Gilvan Müller et al. Terra das Línguas. Manaus: PPGSCA-UFAN/FUND. FORD, 2007. . A cooficialização de línguas em nível municipal no Brasil: direitos linguísticos, inclusão e cidadania. In: MORELLO, Rosângela. Leis e línguas no Brasil: o processo de cooficialização e suas potencialidades. Florianópolis: IPOL, 2015, p. 23-30.

RODRIGUES, Aryon Dall'igna. Línguas brasileiras: para o conhecimento das línguas indígenas. São Paulo: Edições Loyola, 2002.

SANTOS, Boaventura de Sousa. Refundación Del Estado em América Latina: perspectivas desde uma epistemologia del Sur. Lima: Instituto Internacional de Derecho y Sociedad, 2010a.

. (Org.). Reconhecer para libertar: os caminhos do cosmopolitismo multicultural. $2^{\mathrm{a}}$ ed. Rio de Janeiro: Civilização brasileira, 2010b.

SILVA, Fabiana Sarges da. A lei de cooficialização das línguas tukano, nheengatu e baniwa em São Gabriel da Cachoeira: questões sobre política linguística em contexto multilíngue. Manaus: UFAM, 2013. Dissertação (Mestrado em Letras) - Programa de Pós-Graduação em Letras, Universidade Federal do Amazonas, Manaus, 2013.

\section{NOTAS}

${ }^{1} \mathrm{O}$ processo conhecido como nacionalização do ensino passou a considerar "crime idiomático" o uso de qualquer língua que não fosse a língua nacional, o português. Entre 1941 e 1945, o governo ocupou as escolas comunitárias e fechou gráficas e jornais que funcionavam em alemão e em italiano. Em Santa Catarina, o governo criou campos de trabalho forçado para os descendentes de alemão que insistissem em falar a língua alemã. Nas escolas, as crianças eram incentivadas a denunciarem os pais que estivessem usando alemão ou italiano em casa (OLIVEIRA, 2002).

${ }^{2}$ A Língua Brasileira de Sinais (LIBRAS) foi reconhecida como meio legal de comunicação e expressão através da Lei 10.436, em 24 de abril de 2002. (BRASIL, 2002) 
3 http://e-ipol.org/a-politica-de-cooficializacao-de-linguas-por-municipios-e-suas-potencialidades/ - Acesso em 27 de abril de 2016

${ }^{4}$ Federação das Organizações Indígenas do Rio Negro.

Recebido em: 13 de janeiro de 2016

Aceito em: 02 de maio de 2016 